\title{
Relationship between Aerosols Exposure and Lung Deposition Dose
}

\author{
Tobias Hammer ${ }^{1,2}$, Hanchao Gao ${ }^{1,2}$, Zhengyuan Pan ${ }^{1,2}$, Jing Wang ${ }^{1,2 *}$ \\ ${ }^{1}$ Institute of Environmental Engineering, ETH Zürich, 8093 Zürich, Switzerland \\ ${ }^{2}$ Laboratory of Advanced Analytical Technologies, Empa, 8600 Dubendorf, Switzerland
}

\begin{abstract}
We systematically evaluated the relationship between exposure to aerosols—-specifically, ultrafine airborne particlesand the effective dose in the lungs of humans and animals. By multiplying particle concentration size distributions with lung deposition curves generated by the Multiple-Path Particle Dosimetry (MPPD) model, the lung deposition concentrations, which can be directly linked to the effective dose via inhalation rate and exposure time, were estimated.

The calculations were performed on a number of representative particle size distributions extracted from measurement data in the literature. In addition to determining the lung deposited particle concentration, we investigated its possible relationship with the diameter of the main mode for the size distribution. We also examined the potential use of animal surrogates for human beings in inhalation exposure studies.

The average concentration of the deep-lung deposited fraction (the sum of the alveolar and trachea-bronchial deposited concentrations divided by the ambient concentration) depended on the size distribution of the inhaled aerosol and the specific metric (particle number, surface area or mass), being slightly higher when the particle number instead of the surface area or mass was measured. It was also affected by the diameter of the aerosol size distribution's main mode: the smaller the diameter, the larger the lung deposited particle fraction. Our study aims at a better understanding of the correlations between the particle parameters measured in exposure studies and dose metrics in the lung, thereby facilitating an accurate risk assessment of ultrafine ambient particles.
\end{abstract}

Keywords: Lung deposition; Ambient aerosol; Dose; Exposure; Ultrafine particles.

\section{INTRODUCTION}

Due to the recently strongly recognized issue of air pollution by aerosol particles and particularly by anthropogenic ultrafine particles (UFPs) that contribute significantly to the ambient aerosol in the air, there is an increasing need to evaluate the exposure and to assess the potential adverse health effects that could be induced by UFPs in the ambient air.

Air pollution in general has always been of concern in the past and in recent years (Calthrop and Maddison, 1996; Pearce, 1996; Schraufnagel et al., 2019; Vallero, 2019) and therefore extensively studied. Various studies focused on different aspects, e.g., on $\mathrm{PM}_{10}$ (Donaldson and MacNee, 2001; Khan et al., 2010; Gianini et al., 2012; Gao et al., 2019; Li et al., 2019; Piras et al., 2019) or UFP emissions (Lee et al., 2007; Khan et al., 2010; Chen et al., 2016; Li et al., 2019).

Nowadays the research focus lies particularly on the investigation of anthropogenic aerosol particles with diameters

\footnotetext{
${ }^{*}$ Corresponding author.

E-mail address: jing.wang@ifu.baug.ethz.ch
}

smaller than $500 \mathrm{~nm}$, to which ultrafine aerosols contribute significantly, and the potentially induced adverse health effects. Health risks caused by UFPs in the air have been studied (Yeh et al., 1976; Donaldson and MacNee, 2001; Lee et al., 2007; Hankin, 2014; Kumar et al., 2014; Landsiedel et al., 2014; Chen et al., 2016; Guo et al., 2018; Khan et al., 2018; Schraufnagel et al., 2019). In addition to these studies, linking aerosol exposure to the particle dose in the lung could be beneficial to assess the adverse health effects induced by UFPs.

One prominent example for anthropogenic UFPs is soot particles generated in combustion processes. Due to a high number of combustion emissions, such as the emissions from vehicles and airplanes running on fossil fuel, the emissions of the combustion of coal, firewood, liquefied petroleum gas (LPG) etc. (Mathis et al., 2004; Keskinen and Rönkkö, 2010; Wang et al., 2011; Tiwari et al., 2014), there is a high number of anthropogenic UFPs in the air (e.g., measured by the Swiss National Air Pollution Monitoring Network).

In 2010, the world health organization (WHO) classified the soot particles as carcinogenic (WHO, 2010). Since these combustion processes take place mainly in residential and industrial areas, a high number of people might be exposed 
to soot particles. However, people are not only exposed to ultrafine combustion derived soot particles but also other environmental UFPs during daily life.

Employees working in offices might be exposed to UFPs just by inhaling indoor office air. In this case, emissions from laser printers contribute a major fraction to the total concentration of UFPs (Scungio et al., 2017). In some circumstances indoor particle concentration might even be higher than that of the ambient air (Bertrand et al., 2017; Oh et al., 2019). Also the more frequently established 3D printers emit UFPs and contribute to the total UFPs in office air (Stephens et al., 2013).

UFP concentration in ambient air needs to be connected with the deposited particle dose in the lung. Schmid and Cassee (2017) argued that exposure was a poor surrogate for the delivered dose of inhaled nano- or micron-sized particles. However, there is also the contradictory opinion. Manigrasso et al. (2018) explained that exposure to UFPs can be expressed via lung deposited dose. In the present study, the total particle concentration in the ambient air was taken as a reference point to evaluate the actual deposited concentration in the lung, which is directly linked to the delivered dose via the exposure time and the inhalation flowrate.

Particle exposure and lung deposition can be expressed based on different metrics. Besides evaluating lung deposition based on particle number or mass, especially deposition based on surface area, needs to be scrutinized, because the interaction of particles and the lung tissue happens via their surface (Avino et al., 2016; Manigrasso et al., 2018; Hammer et al., 2019). Based on this principle, Schmid and Stoeger (2016) stated that surface area was the biologically most effective dose metric for acute particle toxicity in the lung. Moreover, Schmid and Cassee (2017) argued that dose played a critical role in particle toxicity. However, dose in human or even animal lungs is difficult to measure, but it can be estimated by combining measured particle concentrations and lung deposition curves.

In the present study, we explored how the exposure to aerosols in the ambient air was related to the effective particle dose, and the deposited particle fraction in the lungs of human beings and several selected animals and thus could be linked to adverse or toxicological effects. For this, we compared UFP exposure in ambient air with the lung deposition calculated using the Multiple-Path Particle Dosimetry Model (MPPD). The toxic effects induced by environmental aerosols through the exposure pathway of inhalation, depend not only on the intrinsic toxicity of the particles (chemical composition, size, surface area, shape etc.), but also on the effective dose reaching the deep-lying lung regions such as the trachea-bronchus (TB) or the alveoli (AL) (Hammer et al., 2019; Ivanov, 2013). It was shown that particles reaching these compartments might block the airways or even penetrate into the blood (Dekali et al., 2014; Derk et al., 2015; Zhou et al., 2018). Consequently, we focused particularly on deposition in the deep-lying regions of the respiratory system.

Combining the relevant factors such as inhalation flowrate, exposure time and ambient concentration with the lung deposition curve of the MPPD model (ARA Inc., 2016; Miller et al., 2016) one can estimate the lung deposited dose. Due to different inhalation characteristics of humans and animals, the effective lung dose and the final induced toxicity depend on the deposition target species. For example, pigs have a similar inhalation flowrate $\left(7168 \mathrm{~mL} \mathrm{~min}^{-1}\right)$ compared

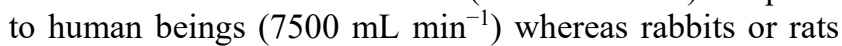
have smaller inhalation flow rates $\left(1189 \mathrm{~mL} \mathrm{~min}^{-1}\right.$ or $204 \mathrm{~mL} \mathrm{~min}^{-1}$ ). We studied aerosol deposition also for rats, rabbits and pigs to show that the deposited aerosol fraction actually also depends on the species and that some of these species are affected more (higher deposited aerosol fraction for humans and rats, although they have different inhalation flowrates) and others are affected less (lower deposited aerosol fraction for pigs and rabbits).

To quantify exposure to ambient UFPs originating from different sources, we investigated diverse aerosol size distributions in the ambient air and occupational settings. The considered cases of aerosols in the environment included the aforementioned emissions from 3D and laser printers, soot particles generated in combustion processes (combustion of diesel, kerosene, firewood, liquefied petroleum gas or dung cake), and ambient particle size distributions.

Albeit the considered size distributions possessed different characteristics such as different diameters of the main modes or broader or narrower modes, they showed also similarities. Their main modes were located in the size range of 5-500 nm. Particle size distributions in this size range overlap with a range where high deposition in the alveolar and trachea-bronchial lung regions occurs (10-250 $\mathrm{nm})$. This overlap plays an important role for the total aerosol deposition concentration and consequently also for the final lung deposited particle dose (Hammer et al., 2019). We investigated the lung deposited concentration of aerosol size distribution and tried to find whether and how it is affected by the considered metric (number, surface area or mass).

Particularly with regard to the exposure assessment for UFPs, our study is of high benefit for the society. An entire toxicity and risk assessment of anthropogenically generated UFPs in the environment would require combining the obtained relationship between the lung deposition and the ambient particle concentration with the particle type (intrinsic toxicity). A first evaluation about the risk of these particle can however be derived by assessing their lung deposition concentration.

\section{MATERIALS AND METHODS}

We calculated the lung deposited particle concentrations for various selected animals and human beings by multiplying measured particle size distributions from literature data with the lung deposition curves, calculated using the MultiplePath Particle Dosimetry model (ARA Inc., 2016; Miller et al., 2016) and integrating within the particle size range of $10-500 \mathrm{~nm}$.

In order to investigate how the considered metric (number, surface or mass) affected the lung deposited fraction, we converted the measured particle number distributions from the literature into surface area or mass distributions by 
multiplying with the surface area or with the volume of a spherical particle and size dependent effective densities.

\section{Utilized Number Size Distributions}

The utilized size distributions were extracted from literature data measured by the Swiss National Air Pollution Monitoring Network and other researchers (Mathis et al., 2004; Keskinen and Rönkkö, 2010; Stephens et al., 2013; Tiwari et al., 2014; Scungio et al., 2017). We considered emissions from 3D and laser printers and emissions from combustion processes (diesel, kerosene, liquefied petroleum gas, firewood or dung cake) and ambient airborne particles. All number size distributions were measured based on the electrical mobility diameter either by (different kinds of) Scanning Mobility Particle Sizers (SMPSs; combustion derived particles, ambient aerosols and 3D printer emissions) or a Fast Mobility Particle Sizer (FMPS) in case of the emissions from laser printers. For comparability reasons and with regard to the assessment of their respective deposition, the number size distributions were normalized by the total number concentration.

Keskinen and Rönkkö (2010) and Mathis et al. (2004) reported that the nucleation mode in the diesel size distribution was found to be dependent on the relative humidity $(\mathrm{RH})$ of the diluting air. For their experiments, the humidity of primary dilution (PRH) was less than 5\%. For the study with the coal, dung cake, firewood, kerosene and LPG size distributions, the authors (Tiwari et al., 2014) mentioned that the RH ranged between $50 \%$ and $75 \%$ for all the measurements. The utilized size distributions of the monitoring station of the Swiss National Air Pollution Monitoring Network (NABEL) in Zürich for summer and winter 2017 were averages over one month in each case. The investigated time range contained dry periods and rain events, and therefore varying $\mathrm{RH}$ values. An average over one month compensated daily variable events, such as the effects of RH. For the laser printer emissions, the $\mathrm{RH}$ was continuously controlled. The monitored $\mathrm{RH}$ values were $50 \pm 10 \%$ (Scungio et al., 2017). Therefore, most of the aerosol data used in this study were measured with $\mathrm{RH}$ range of $40-75 \%$ and the effect on measurements by FMPS and SMPS was not expected to be strong. Fig. 1 depicts the considered number size distributions of ambient air, soot particles and printer emissions.

As shown in Fig. 1, the main modes of the utilized size distributions are in the size range of 5-500 $\mathrm{nm}$. Some distributions (e.g., the ambient particles measured by the

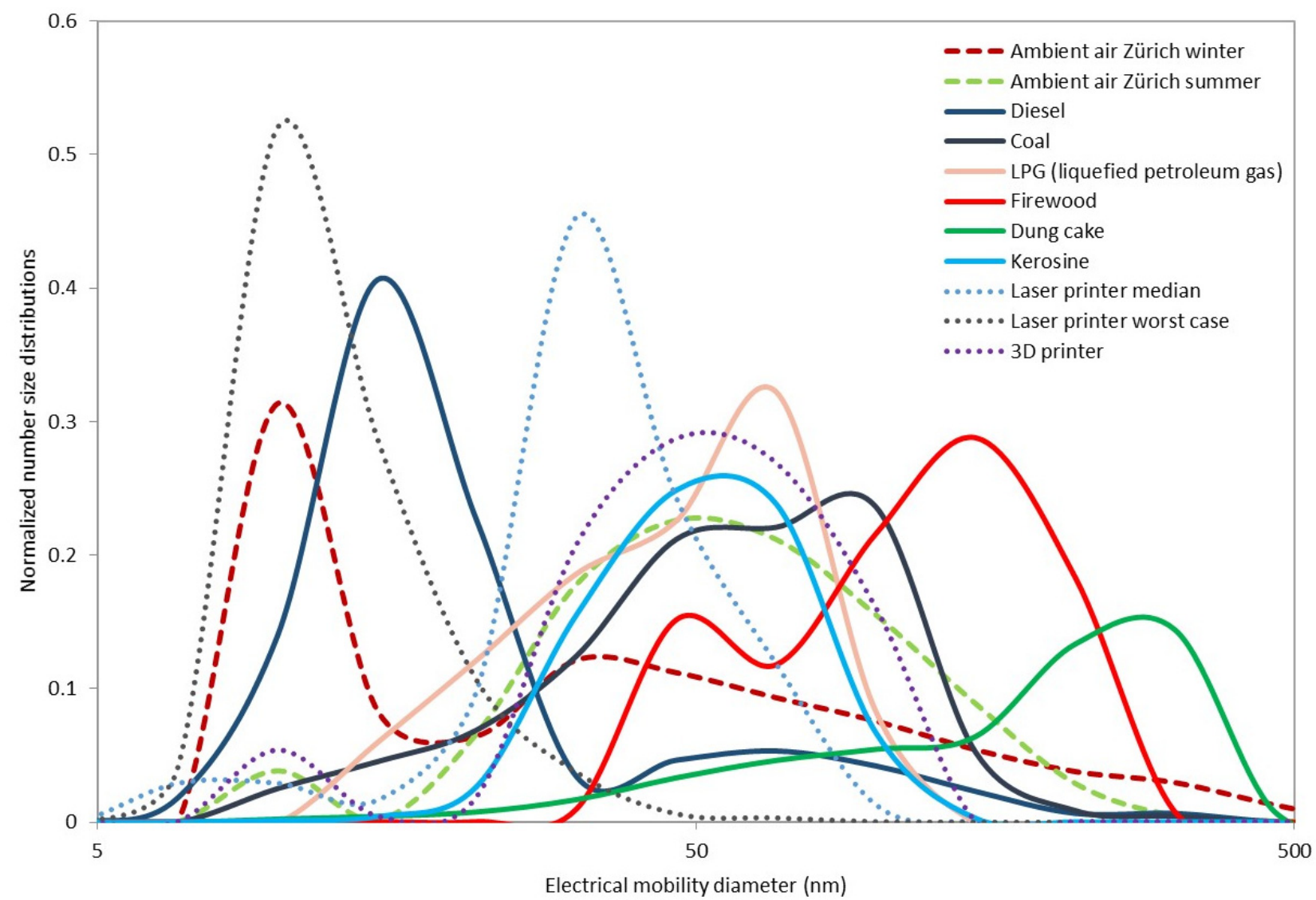

Fig. 1. Normalized size distributions extracted from the literature: Ultrafine particles in ambient air for winter and summer 2017 in Zürich from the Swiss NABEL, soot particles from the combustion of diesel, coal, liquefied petroleum gas (LPG), firewood, dung cake and kerosene and particle emissions from 3D and laser printers ("Laser printer worst case" refers to the laser printer emitting particles with the smallest diameters among several laser printers; "Laser printer median" is their median size distribution) from Mathis et al. (2004), Keskinen and Rönkkö (2010), Stephens et al. (2013), Tiwari et al. (2014) and Scungio et al. (2017). 
Swiss NABEL for summer 2017 in Zürich) show rather broad modes. Some contain one major mode (e.g., laser printer emissions) whereas others are multimodal (e.g., the ambient particles measured by the Swiss National Air Pollution Monitoring Network at the NABEL station for winter 2017 in Zürich). In addition, a broad variety of diameters of main modes of the size distribution was covered with these different size distributions. Laser printers for example emitted rather small particles whereas others such as combustion of firewood or dung cake emitted rather big particles. To derive the so-called "main mode" we fitted the single modes in the size distributions using lognormal functions in the Origin software. For multimodal size distributions, the diameter of the main mode was calculated as weighted average of the modes in the size distribution considering the area of each mode. The areas of each mode were used to calculate their relative percentage. The percentages were multiplied with the mode diameter and summed up. The result gave the diameter of the main mode.

\section{Conversion of the Electrical Mobility Diameter into the Aerodynamic Diameter}

The multiplication of measured size distributions with the lung deposition curves was only possible if both functions utilized the same particle diameter. All the extracted number size distributions from literature data were measured based on the electrical mobility diameter $\left(d_{m}\right)$ whereas the lung deposition curves calculated by the MPPD model used the aerodynamic diameter $\left(d_{a}\right)$. Especially, if the effective particle density strongly depended on the particle diameter or if the particles had high density, there would be a significant difference between these two diameters. Thus, we converted the measured electrical mobility diameter into the aerodynamic diameter for all size distributions.

Particularly for soot aerosols, the effective particle density was strongly dependent on the particle diameter. Hence, we explain the conversion exemplarily for soot particles. Similarly, the diameters of the ambient aerosols and printer emission size distributions were converted by applying Formula (1) from Hammer et al. (2019):

$$
d_{a}=\sqrt{\frac{\rho_{p} C_{\mathrm{C}}\left(d_{e}\right)}{\rho_{0} \chi C_{\mathrm{C}}\left(d_{a}\right)}} \cdot d_{e}=\sqrt{\frac{\rho_{p} C_{\mathrm{C}}\left(d_{m}\right)}{\rho_{0} \chi C_{\mathrm{C}}\left(d_{a}\right)}} \cdot \sqrt[3]{\frac{a d_{m}^{D_{f}}}{\rho_{p}}}
$$

where the particle density of carbon (main component of soot) $\rho_{p}=2146 \mathrm{~kg} \mathrm{~m}^{-3}$; density $\rho_{0}=1000 \mathrm{~kg} \mathrm{~m}^{-3}$; and a shape factor $\chi=1$ for the first approximation, the Cunningham slip corrections $C_{C}\left(d_{m}\right), C_{C}\left(d_{e}\right), C_{C}\left(d_{a}\right)$ of the mobility diameter $d_{m}$, the volume equivalent sphere diameter $d_{e}$ and the aerodynamic diameter $d_{a}$, the mass mobility exponent of the particle $D_{f}$ and a pre-factor $a$, which also accounts for the unit of $\mathrm{kg} \mathrm{m}^{-3}$. For soot aerosols a $D_{f}$ of 2.5 and a pre-factor of 0.2 were assumed as in Durdina et al. (2014) and Hammer et al. (2019). We calculated the $C_{C}\left(d_{m}\right)$ and $C_{C}\left(d_{e}\right)$ for the investigated size range below $500 \mathrm{~nm}$. Their values were nearly equal. For this study, we assumed equal values.

The discrepancy between $d_{a}$ and $d_{m}$ became obvious especially in case of large soot aerosols as shown in Fig. 2. For diameters smaller than $86 \mathrm{~nm}$, the difference between the two diameters lay within the range of several nanometers and $d_{a}$ was slightly larger than $d_{m}$. Once the particle mobility diameter exceeded $86 \mathrm{~nm}, d_{a}$ was smaller than $d_{m}$.

\section{Conversion of Number Distributions into Surface Area and Mass Distributions}

In order to get the corresponding surface area distributions, the measured particle number size distributions were multiplied by the surface area of a sphere. The assumption of spherical particles was consistent with the assumption applied in the underlying measurement technique, the SMPS to obtain the particle number size distributions. In addition, the number size distributions were converted into mass distributions by multiplying with the volume of a sphere and size dependent effective particle densities. For ambient aerosols and printer emissions, the effective aerosol densities showed nearly constant values independent of the diameter. For ambient aerosols a particle density of $1.2 \mathrm{~g} \mathrm{~cm}^{-3}$ was presumed by the Swiss National Air Pollution Monitoring Network. For the emissions from 3D printers the particle density was $2 \mathrm{~g} \mathrm{~cm}^{-3}$ (Stephens et al., 2013) and for laser

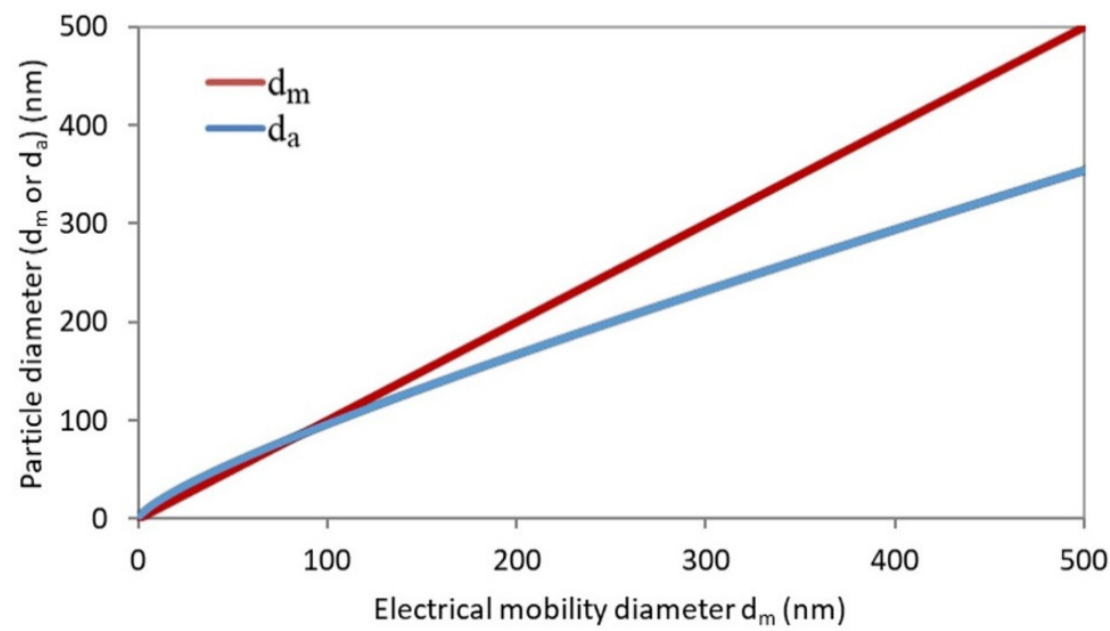

Fig. 2. Discrepancy of the aerodynamic diameter $\left(d_{a}\right)$ and the electrical mobility $\left(d_{m}\right)$ for soot aerosols. 
printer emissions a value of $2 \mathrm{~g} \mathrm{~cm}^{-3}$ was measured by Scungio et al. (2017).

However, the effective density was strongly dependent on the particle diameter for soot aerosols as shown in Formula (2) from Durdina et al. (2014). By comparing size dependent effective density curves, we identified that this equation was applicable for different kinds of combustion derived soot particles.

$$
\rho_{\text {eff }}\left(\mathrm{kg} \mathrm{m}^{-3}\right)=0.2 d_{m}^{2.5-3}
$$

\section{Definition of Lung Deposited Concentration and Effective Lung Deposited Particle Dose}

The effective lung deposited dose depended on several factors such as the lung deposited particle concentration, the exposure time and the inhalation flowrate of the considered target (human being or animals). It is shown in Formula (3).

effective lung deposited dose $=$ lung deposited particle concentration $\left(\mathrm{d}_{\mathrm{a}}\right) \times$ exposure time $\times$ inhalation flowrate

Exposure time and inhalation flowrate act principally as scaling factors. A comparison among different targets (human being or animals) needs to be done via the lung deposited particle concentration or the lung deposited aerosol fraction. We calculated the lung deposited particle concentration specifically for the deep-lying lung regions (AL, TB and AL $+\mathrm{TB}$ ) and based on different metrics (number, surface area and mass). It depends on the particle size as shown in Formula (4).

lung deposited particle concentration $\left(\mathrm{d}_{\mathrm{a}}\right)=$ aerosol concentration of a particle size distribution at a specific size $\left(d_{a}\right) \times$ MPPD deposition efficiency in the AL, TB or $\mathrm{AL}+\mathrm{TB}$ at a specific size $\left(\mathrm{d}_{\mathrm{a}}\right)$

where the aerosol concentration is either in $\# \mathrm{~cm}^{-3}, \mathrm{~m}^{2} \mathrm{~cm}^{-3}$ or $\mathrm{g} \mathrm{cm}^{-3}$.

The integration of the size dependent lung deposited particle concentration over the considered size range and dividing the result by the total aerosol corresponds to the dimensionless lung deposited particle fraction (shown in Formula (5)).

lung deposited particle fraction $=$

$$
\frac{\int \text { lung deposited concentration }\left(d_{a}\right)}{\int \text { aerosol concentration in the ambient air }\left(d_{a}\right)}
$$

\section{Calculation of the Lung Deposition Using the MPPD Model}

We employed the MPPD model (ARA Inc., 2016; Miller et al., 2016) for the assessment of the lung deposited particle concentrations. Generally, the considered lung morphology in the MPPD model was dividable into three parts: head airways, trachea-bronchus and the pulmonary region, which corresponds to the alveoli. We calculated the deposited particle concentrations in the deep lung (alveoli and trachea-bronchus). Here, we devoted a focused discussion on the deposition mechanisms of the MPPD model. Based on Yeh and Schum (1980), the total deposition efficiency, $P_{\sum}$, was the sum of the deposition by diffusion $P_{D}$, the deposition by impaction $P_{I}$ and the deposition by sedimentation $P_{S}$ (Formula (6)). Deposition by diffusion is the dominant deposition mechanism for small particles $(<300 \mathrm{~nm})$. Impaction and sedimentation are significant for bigger particles. Therefore, big particles deposit mainly by impaction and sedimentation in the head airways and in the trachea-bronchus. Small particles deposit by diffusion mainly in alveolar and also the trachea-bronchial lung parts and just to a small degree in the head airways.

$P_{\Sigma}=P_{D}+P_{s}+P_{I}$

The different sub-terms of the deposition $P_{\Sigma}$ depended on the considered target (human being or animals) and on their activity. For more information see also Yeh and Schum (1980), ARA Inc. (2016), Miller et al. (2016) and Hammer et al. (2019). With the help of the following equations from Yeh and Schum (1980) the dependencies on the airway radius $R$, the length of the airway segment $L$ or the airflow velocity $\bar{v}$ could be explained in more detail. Assuming laminar flow, the probability for deposition by diffusion $P_{D}$ was defined by the factor $x$, which depended on the aforementioned factors and the diffusion coefficient of particles $D$ :

$$
x=\frac{L D}{2 R^{2} \bar{v}}
$$

for which $P_{D}$ was:

$$
\begin{aligned}
P_{D} & =1-0.819 e^{-7.135 x}-0.0976 e^{-44.61 x}-0.325 e^{-114 x} \\
& -0.0509 e^{-114 x}-0.0509 e^{-79.31 x^{2 / 3}}
\end{aligned}
$$

The deposition by sedimentation was defined by the probability for sedimentation $P_{S}$, the density of a particle $\rho_{p}$ and the inclination angle relative to gravity $\varnothing\left(\varnothing=0^{\circ}\right.$ for a horizontal tube).

$$
P_{S}=1-\exp \frac{-4 g C_{C}\left(d_{a}\right) \rho_{p} r_{p}^{2} L \cos \varnothing}{9 \pi \mu R \bar{v}}
$$

The deposition probability for impaction $P_{I}$ depended on the branching angle (in radians) $\theta$ and the Stokes number Stk:

$S t k=\frac{C_{C}\left(d_{a}\right) \rho_{p} r_{p}^{2} \bar{v}}{9 \mu R}$

where $r_{p}$ was the radius of the particle and $\mu$ was the viscosity of the fluid: 
$P_{I}=1-\frac{2}{\pi} \cos ^{-1}(\theta \cdot S t k)+\frac{1}{\pi} \sin \left(\cos ^{-1}(\theta \cdot S t k)\right)$

for $\theta \cdot$ Stk $<1$

$$
P_{I}=1 \text { for } \theta \cdot S t k \geq 1
$$

We calculated the deposition of UFPs in the lungs of human beings and several animals including pig, rat and rabbit and investigated whether there was a best animal surrogate concerning inhalation exposure studies by investigating the similarities of the lung deposited particle fractions.

Fig. 3 shows the particle deposition efficiencies with increasing particle diameters. From $10 \mathrm{~nm}$ all TB deposition curves decrease with increasing particle diameter. Only the TB deposition curve slightly increases above $120 \mathrm{~nm}$. The human TB deposition curve shows by far the highest deposition values at small particle diameters. It starts with the highest value of $47 \%$ at a particle diameter of $10 \mathrm{~nm}$ followed by rat with $28 \%$, rabbit with $21 \%$ and pig with $13 \%$, which shows the lowest deposition.

In case of particle deposition in the alveoli, the shape of the deposition curve is slightly different. All deposition curves show a peak point where the highest deposition occurs. The AL deposition curves of rats and humans peak at about $35 \mathrm{~nm}$ with values of $31.3 \%$ and $29.4 \%$. In addition, their shapes are similar. The AL deposition curves of rabbit (37.1\%) and pig (20.5\%) peak at smaller diameters, about $23 \mathrm{~nm}$ for pig and about $18 \mathrm{~nm}$ for rabbit. With regard to total deposition in the deep lung, we combined the deposition in the $\mathrm{AL}$ and $\mathrm{TB}$ regions to $\mathrm{AL}+\mathrm{TB}$.

\section{RESULTS AND DISCUSSION}

With the focus on UFP deposition in the deep lung regions, we scrutinized the deposited particle concentration in the alveolar and trachea-bronchial regions. We investigated if there was a correlation of the total alveolar, trachea-bronchial or $\mathrm{AL}+\mathrm{TB}$ deposition and the particle concentrations in the ambient air. The main results are summarized in Fig. 4, Fig. 5 and Table 1.

Fig. 4 shows the calculated lung deposited concentrations in the $\mathrm{AL}+\mathrm{TB}, \mathrm{AL}$ and $\mathrm{TB}$ for all considered aerosol size distributions based on different metrics - number (Fig. 4(a)), surface area (Fig. 4(b)) and mass (Fig. 4(c))) for human beings, pigs, rats and rabbits versus the measured ambient particle concentrations. The shown values represent the total deposited concentrations after integration. The calculated total deposition concentration correlates with the measured particle concentration in the ambient air: the higher the concentration of ultrafine particles in the ambient air, the higher also the deposited lung deposited concentration. In case of mass as the considered metric the increasing trend is influenced by the density of the particles.

The average slopes of the correlations in Fig. 4 were compiled in Table 1 . The values corresponded to the average deposited particle fraction. It is difficult to distinguish the single points in Fig. 4, but we were mainly interested in the slopes of these correlations.

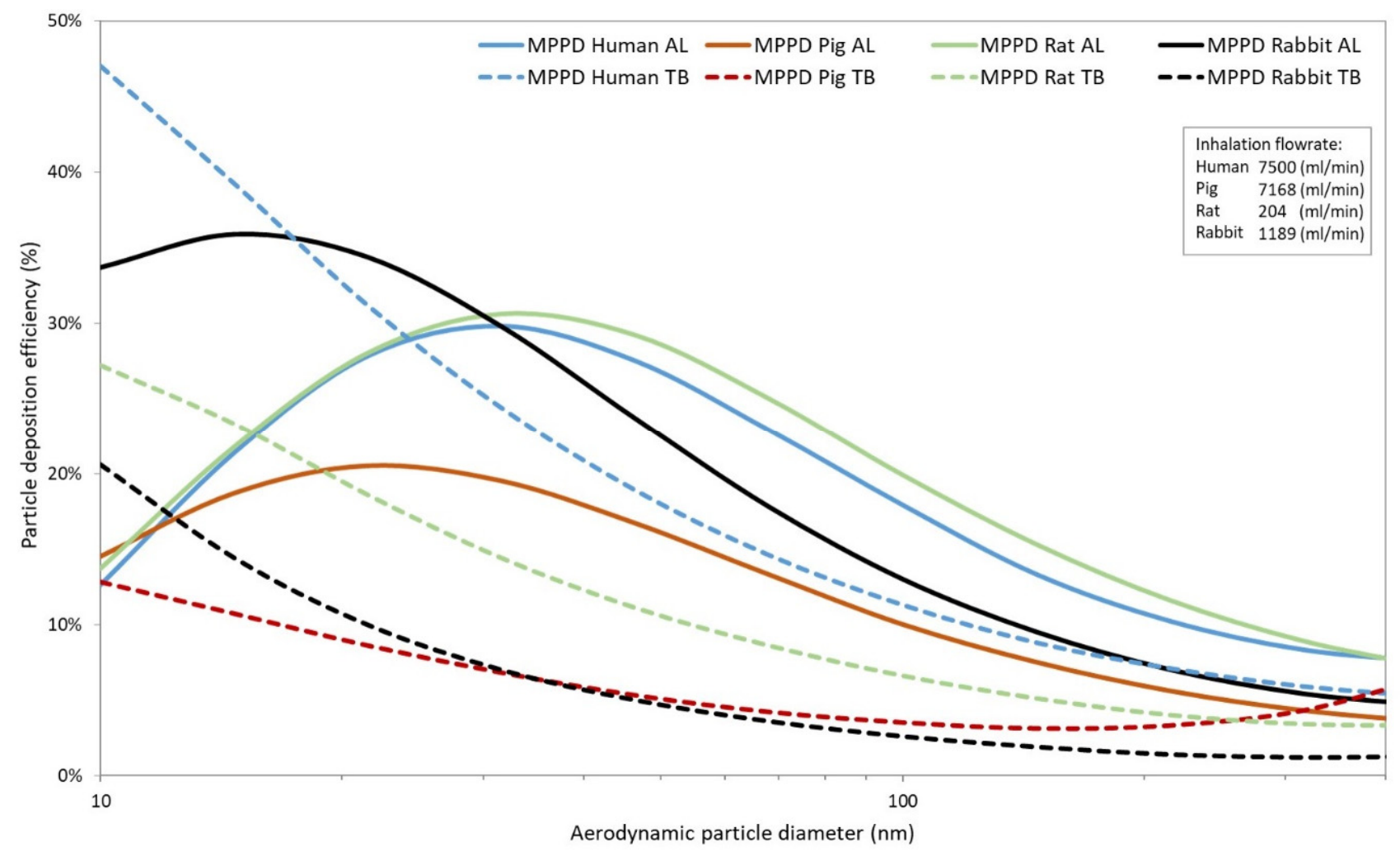

Fig. 3. Size dependent particle deposition efficiencies in the alveolar (AL) and trachea-bronchial (TB) regions of human and animal lungs (modified from Hammer et al., 2019). 

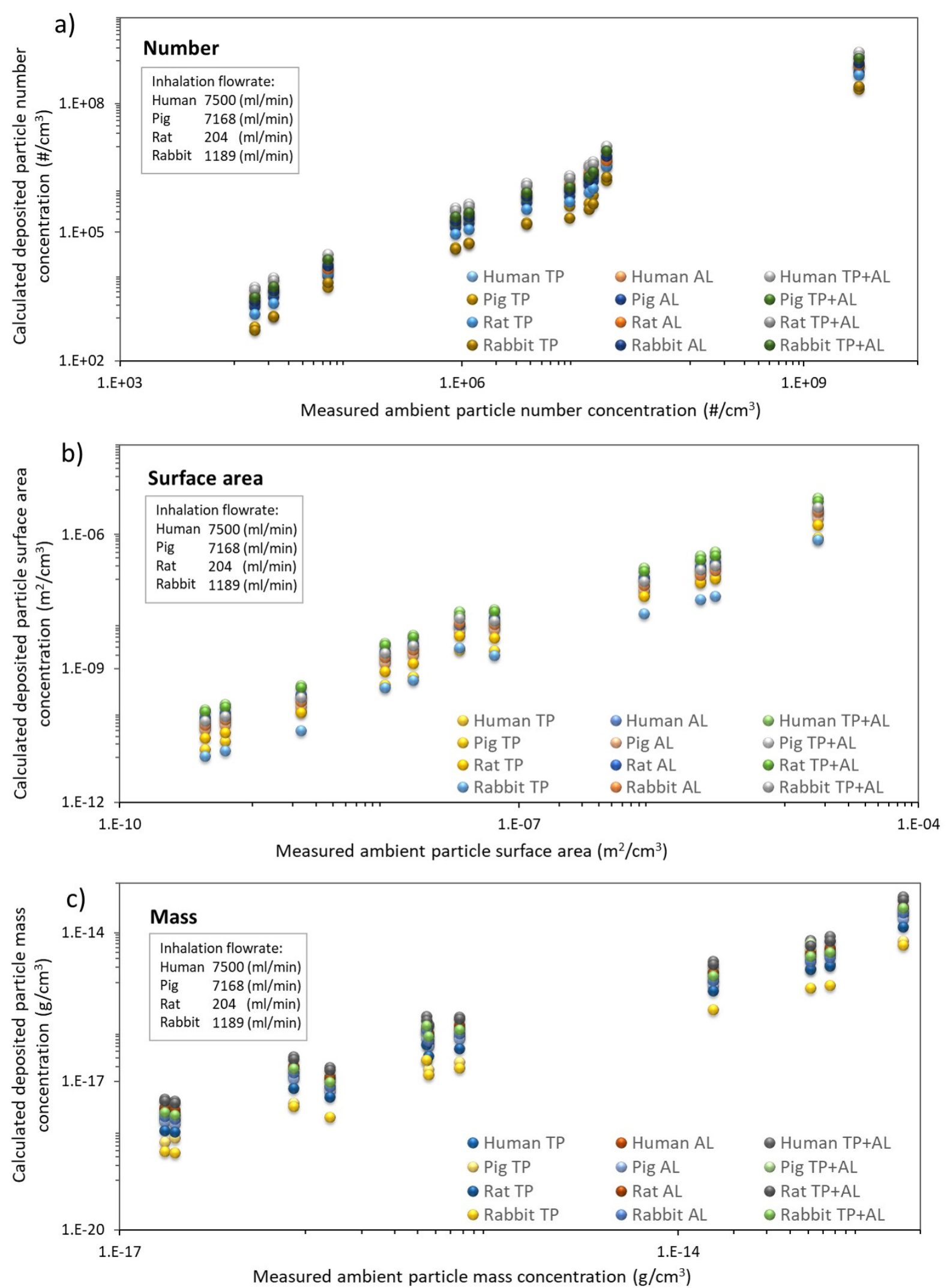

Fig. 4. Lung deposited particle concentrations in the alveoli (AL) and trachea-bronchus (TB) and AL + TB for various aerosols, calculated based on different concentration metrics (number, surface area and mass) for human beings, pigs, rats and rabbits versus the measured ambient particle concentrations (number, surface area and mass). (a) shows the lung deposited particle concentrations based on number; (b) and (c) show the lung deposited particle concentrations based on surface area and mass. 

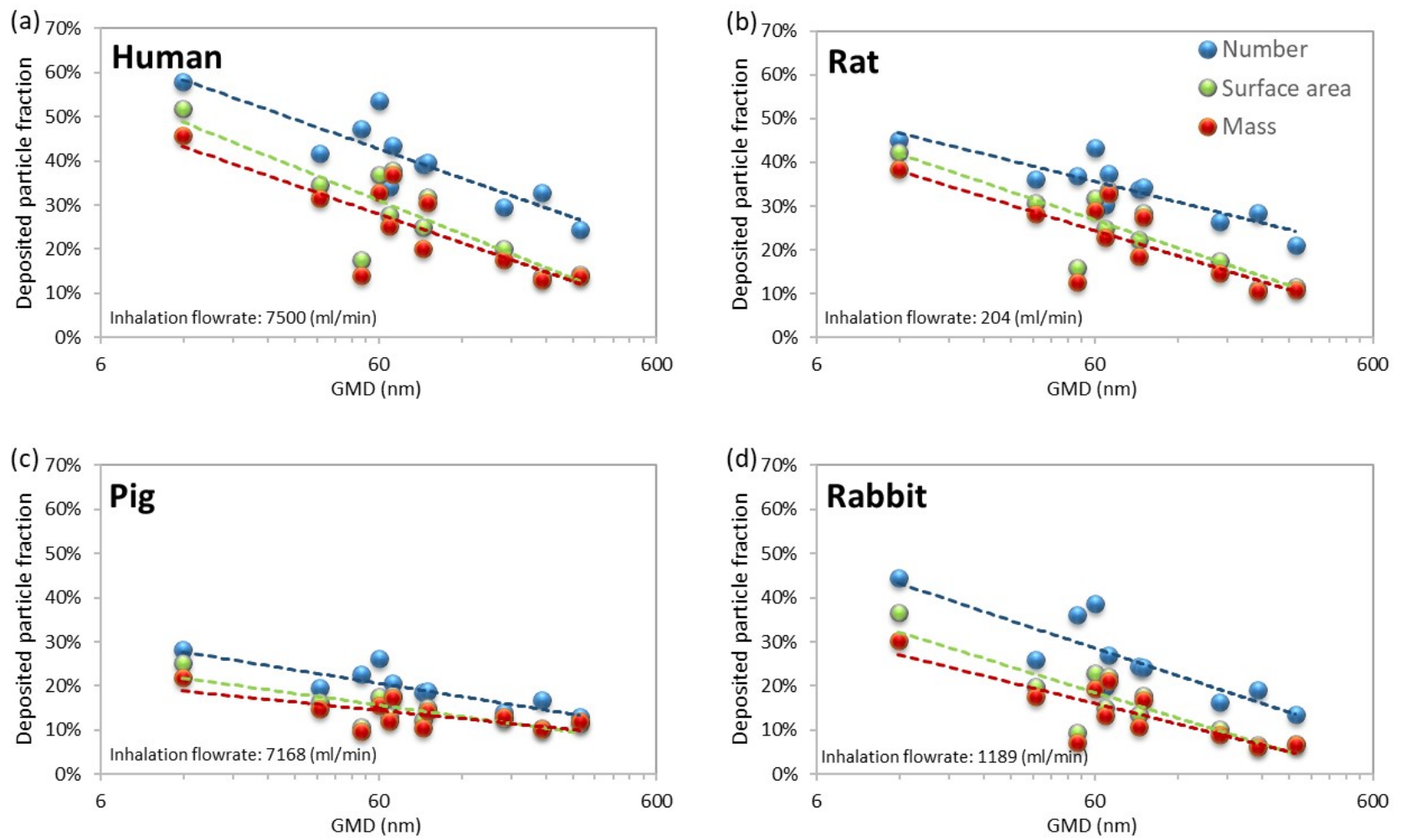

Fig. 5. Dependency of the lung deposited aerosol fractions in $\mathrm{AL}+\mathrm{TB}$ on the diameter of the main mode for various targets: (a) human, (b) rat, (c) pig, (d) rabbit.

Table 1. Deposited particle fractions in alveoli (AL), trachea-bronchus (TB) and AL+TB for various aerosols based on different concentration metrics (number, surface area and mass). The applied inhalation flowrates were $7500 \mathrm{~mL} \mathrm{~min}^{-1}$ for humans, $7186 \mathrm{~mL} \mathrm{~min}^{-1}$ for pigs, $204 \mathrm{~mL} \mathrm{~min}^{-1}$ for rats and $1189 \mathrm{~mL} \mathrm{~min}^{-1}$ for rabbits.

\begin{tabular}{|c|c|c|c|c|c|c|c|c|c|}
\hline & \multicolumn{3}{|c|}{ Number } & \multicolumn{3}{|c|}{ Surface area } & \multicolumn{3}{|c|}{ Mass } \\
\hline & TB & $\mathrm{AL}$ & $\mathrm{AL}+\mathrm{TB}$ & TB & $\mathrm{AL}$ & $\mathrm{AL}+\mathrm{TB}$ & TB & $\mathrm{AL}$ & $\mathrm{AL}+\mathrm{TB}$ \\
\hline Human & $19 \%$ & $21 \%$ & $40 \%$ & $12 \%$ & $16 \%$ & $28 \%$ & $11 \%$ & $15 \%$ & $26 \%$ \\
\hline Pig & $6 \%$ & $13 \%$ & $19 \%$ & $5 \%$ & $10 \%$ & $15 \%$ & $5 \%$ & $9 \%$ & $14 \%$ \\
\hline Rat & $11 \%$ & $23 \%$ & $34 \%$ & $7 \%$ & $18 \%$ & $25 \%$ & $6 \%$ & $16 \%$ & $22 \%$ \\
\hline Rabbit & $6 \%$ & $20 \%$ & $26 \%$ & $3 \%$ & $13 \%$ & $16 \%$ & $3 \%$ & $12 \%$ & $15 \%$ \\
\hline
\end{tabular}

As shown in Table 1, the deposited fraction was affected by the different targets (human, pig, rat, rabbit) and the concentration metrics (number, surface area, mass). Aerosol deposition in the deep lung was higher in terms of number as compared to surface area and mass. In the human case, this corresponded to $40 \%$ (number) compared to $28 \%$ (surface area) and $26 \%$ (mass). Since lung deposition efficiency curves of rats and human beings were relatively close, also their lung deposited particle fractions were similar. The same held true when number, surface area or mass was the considered metric. $34 \%$ of the ambient particles were deposited in the lungs of rats based on number as the considered metric and $25 \%$ or $22 \%$ in case of surface area or mass. The deposition fractions in the lungs of pigs and rabbits were $26 \%$ and $19 \%$ based on number, $16 \%$ and $15 \%$ based on surface area and $15 \%$ and $14 \%$ based on mass. Due to this similarity rat among the considered animals was the best surrogate for inhalation exposure studies. Independent of the considered target (human being or animals), deposition fractions based on surface area and mass were to some extent smaller than deposition fractions based on number. Comparing deposition in the alveoli and the trachea-bronchus, the alveolar deposited particle fraction was in any case higher than or at least equal to the trachea-bronchial deposited particle fraction.

A further interesting point was the investigation if the lung deposited particle fraction depended on the diameter of the main mode of the considered ambient particle size distributions. According to Fig. 5, the deposited particle fraction decreased with increasing diameter of the main mode of a size distribution. This trend is strongly pronounced for the human case, less for rats and rabbits and marginal for pigs, indicated by the slopes of the fitting lines in Fig. 5. Up to 58\% of the particles from laser printers (worst case) with a very narrow size distribution and a diameter of the main mode of $11.8 \mathrm{~nm}$ were deposited in the deep lung; for soot particles generated in the combustion of dung cake with a diameter of the main mode of $268 \mathrm{~nm}$, the deposited fraction was down to $24 \%$.

The comparison of the average slopes of the deposited 
particle fraction versus the diameter of the main mode, plotted in Fig. 5, showed that there were differences between human beings and the considered animals. This implies that the targeted species needs to be considered in, e.g., a toxicity assessment. In the human case, the fitting lines showed steep slopes indicating a stronger dependency of the lung deposited aerosol fraction on the diameter of the main mode compared to rats, pigs or rabbits. In case of pigs, the fitting lines were almost flat indicating that aerosol deposition in the lungs of pigs was not strongly influenced by the diameter of the main mode of the ambient aerosol.

The main goal of this study was to investigate the relationship between the airborne UFP concentration in ambient air and the lung deposited particle concentration. We found such a relationship by estimating the lung deposited fractions of various ambient aerosol size distributions using the lung deposition curves of the MPPD model for human beings and animals. However, the lung deposited fractions depended also on the main mode of the considered size distributions: the smaller the main mode of the considered size distribution, the higher the lung deposited particle fraction. As aforementioned, the lung deposited particle fraction is directly linked to the effective dose via factors such as the inhalation flowrate and the exposure time. However, these factors basically function as scaling factors. Considering equal exposure time and the different inhalation flowrates of $7500 \mathrm{~mL} \mathrm{~min} \mathrm{~m}^{-1}$ for human beings, $204 \mathrm{~mL} \mathrm{~min}^{-1}$ for rats, $7168 \mathrm{~mL} \mathrm{~min}^{-1}$ for pigs and $1189 \mathrm{~mL} \mathrm{~min}^{-1}$ for rabbits, the effective doses for humans and pigs would be much higher compared to those of rabbits and particularly rats. Thus, humans and pigs would be affected to a higher degree by inhaling the same size distribution. We focus our investigation primarily on the lung deposited particle fraction, which can be compared more effectively.

Considering all lung deposition results of all particle size distributions in this study (Table 1), we can conclude that particle deposition in the alveoli is in any case higher than or at least equal to that in the trachea-bronchus and that the considered metric (number, surface area or mass) and target (human being or animals) affect the deposited particle fraction.

We compared the lung deposited particle fractions of human beings and several animals in order to find a potential animal surrogate for human beings in exposure studies. Based on our calculations, particle deposition in the lungs of rats was similar to that in the lungs of human. Thus, rats could be such a surrogate.

In the present study, we focused on the deposition of aerosols with different size distributions in the deep lung. In the future, it might also be interesting to investigate the effect of humidity (in the ambient air or in the lung) on the aerosol deposition in the lung. Moreover, the aerosol deposition could be linked with the intrinsic aerosol particle toxicity, which would allow determining the effective toxicity of UFPs.

\section{CONCLUSION}

We assessed the exposure to UFPs in the ambient air and in different occupational settings using lung deposition values calculated by the MPPD model. We also investigated the deposited particle concentration's relationship with the particle size distribution as well as individual regions of the respiratory system (the trachea-bronchus and alveoli) for human beings and animals by employing the particle number, surface area and mass as metrics.

The average lung deposited particle concentration (the sum of the alveolar and trachea-bronchial deposited concentrations divided by the ambient concentration) was positively correlated with the total concentration of the ambient aerosol and weakly dependent on the considered metric: the higher the ambient UFP concentration, the larger the deposition in the alveoli and trachea-bronchus.

In all cases, the average alveolar and trachea-bronchial deposited fractions were larger when measured by particle number than by surface area or mass. Compared to the other studied species, human beings exhibited larger fractions of deposited UFPs in the alveoli and trachea-bronchus. Furthermore, these fractions were affected by the diameters of the size distributions' main modes: Smaller diameters resulted in larger fractions. Based on our comparison of the effects on human beings versus other species, rats may be a suitable surrogate for humans in exposure studies. Our study aims at a better understanding of the relationship between the particle parameters measured in exposure studies and dose metrics in the lung, thereby facilitating an accurate risk assessment of ultrafine ambient particles.

\section{NOTES}

The authors declare no competing financial interest.

\section{ACKNOWLEDGEMENTS}

The authors thank Prof. Heinz Fissan for helpful discussion and acknowledge Dr. Martin Steinbacher and the Swiss National Air Pollution Monitoring Networkoperated by Empa and the Swiss Federal Office for the Environment - for the provision of size distribution aerosol data in Zürich.

\section{SUPPLEMENTARY MATERIAL}

Supplementary data associated with this article can be found in the online version at http://www.aaqr.org.

\section{REFERENCES}

Applied Research Associates, Inc. (ARA Inc.) (2016). Multiple-Path Particle Dosimetry Model (MPPD v 3.04). Applied Research Associates, Inc., Raleigh, NC, USA.

Avino, P., Protano, C., Vitali, M. and Manigrasso, M. (2016). Benchmark study on fine-mode aerosol in a big urban area and relevant doses deposited in the human respiratory tract. Environ. Pollut. 216: 530-537. https://doi.org/10.10 16/j.envpol.2016.06.005

Bertrand, A., Stefenelli, G., Bruns, E.A., Pieber, S.M., Temime-Roussel, B., Slowik, J.G., Prévôt, A.S.H., Wortham, H., El Haddad, I. and Marchand, N. (2017). 
Primary emissions and secondary aerosol production potential from woodstoves for residential heating: Influence of the stove technology and combustion efficiency. Atmos. Environ. 169: 65-79. https://doi.org/10.1016/j.at mosenv.2017.09.005

Calthrop, E. and Maddison, D. (1996). The dose-response function approach to modelling the health effects of air pollution. Energy Policy 24: 599-606. https://doi.org/10. 1016/0301-4215(96)00047-X

Chen, R., Hu, B., Liu, Y., Xu, J., Yang, G., Xu, D. and Chen, C. (2016). Beyond $\mathrm{PM}_{2.5}$ : The role of ultrafine particles on adverse health effects of air pollution. Biochim. Biophys. Acta 1860: 2844-2855. https://doi.org/10.1016/ j.bbagen.2016.03.019

Dekali, S., Gamez, C., Kortulewski, T., Blazy, K., Rat, P. and Lacroix, G. (2014). Assessment of an in vitro model of pulmonary barrier to study the translocation of nanoparticles. Toxicol. Rep. 1: 157-171. https://doi.org/10. 1016/j.toxrep.2014.03.003

Derk, R., Davidson, D.C., Manke, A., Stueckle, T.A., Rojanasakul, Y. and Wang, L. (2015). Potential invitro model for testing the effect of exposure to nanoparticles on the lung alveolar epithelial barrier. Sens. Bio-Sens. Res. 3: 38-45. https://doi.org/10.1016/j.sbsr.2014.12.002

Donaldson, K. and MacNee, W. (2001). Potential mechanisms of adverse pulmonary and cardiovascular effects of particulate air pollution $\left(\mathrm{PM}_{10}\right)$. Int. J. Hyg. Environ. Health 203: 411-415. https://doi.org/10.1078/1438-463900059

Durdina, L., Brem, B.T., Abegglen, M., Lobo, P., Rindlisbacher, T., Thomson, K.A., Smallwood, G.J., Hagen, D.E., Sierau, B. and Wang, J. (2014). Determination of PM mass emissions from an aircraft turbine engine using particle effective density. Atmos. Environ. 99: 500-507. https://doi.org/10.1016/j.atmosenv.2014.10.018

Gao, S., Cong, Z., Yu, H., Sun, Y., Mao, J., Zhang, H., Ma, Z., Azzi, M., Yang, W., Jiang, Y., Chen, L. and Bai, Z. (2019). Estimation of background concentration of PM in Beijing using a statistical integrated approach. Atmos. Pollut. Res. 10: 858-867. https://doi.org/10.1016/j.apr.20 18.12.014

Gianini, M.F.D., Gehrig, R., Fischer, A., Ulrich, A., Wichser, A. and Hueglin, C. (2012). Chemical composition of $\mathrm{PM}_{10}$ in Switzerland: An analysis for 2008/2009 and changes since 1998/1999. Atmos. Environ. 54: 97-106. https://doi.org/10.1016/j.atmosenv.2012.02.037

Guo, M., Lyu, Y., Xu, T., Yao, B., Song, W., Li, M., Yang, X., Cheng, T. and Li, X. (2018). Particle size distribution and respiratory deposition estimates of airborne perfluoroalkyl acids during the haze period in the megacity of Shanghai. Environ. Pollut. 234: 9-19. https://doi.org/10.1016/j.envpol.2017.10.128

Hammer, T., Fissan, H. and Wang, J. (2019). Determination of the delivered dose of nanoparticles in the tracheabronchial and alveolar regions of the lung. NanoImpact. 14: 100162. https://doi.org/10.1016/j.impact.2019.100162

Hankin, S. (2014). State-of-the-science in Metrology \& Metrics for Nanomaterials Regulation. Topic 3: Metrology and dose metrics for hazard and exposure assessment throughout the life cycle. Institute of Occupational Medicine, UK, https://echa.europa.eu/documents/10162/ 22816050/9 hankin_ws_nanomaterials_en.pdf/536b945 d-5d0a-4d99-a2b9-9cd9c7a14692

Ivanov, K.P. (2013) Circulation in the lungs and microcirculation in the alveoli. Respir. Physiol. Neurobiol. 187: 26-30. https://doi.org/10.1016/j.resp.2013.02.022.

Keskinen, J. and Rönkkö, T. (2010). Can real-world diesel exhaust particle size distribution be reproduced in the laboratory? A critical review. J. Air Waste Manage. Assoc. 60: 1245-1255. https://doi.org/10.3155/1047-3289.60.10. 1245

Khan, J., Ketzel, M., Kakosimos, K., Sørensen, M. and Jensen, S.S. (2018). Road traffic air and noise pollution exposure assessment - A review of tools and techniques. Sci. Total Environ. 634: 661-676. https://doi.org/10.1016/ j.scitotenv.2018.03.374

Khan, M.F., Shirasuna, Y., Hirano, K. and Masunaga, S. (2010). Characterization of $\mathrm{PM}_{2.5}, \mathrm{PM}_{2.5-10}$ and $\mathrm{PM}_{>10}$ in ambient air, Yokohama, Japan. Atmos. Res. 96: 159-172. https://doi.org/10.1016/j.atmosres.2009.12.009

Kumar, P., Morawska, L., Birmili, W., Paasonen, P., Hu, M., Kulmala, M., Harrison, R.M., Norford, L. and Britter, R. (2014). Ultrafine particles in cities. Environ Int. 66: 1-10. https://doi.org/10.1016/j.envint.2014.01.013

Landsiedel, R., Ma-Hock, L., Hofmann, T., Wiemann, M., Strauss, V., Treumann, S., Wohlleben, W., Gröters, S., Wiench, K. and van Ravenzwaay, B. (2014). Application of short-term inhalation studies to assess the inhalation toxicity of nanomaterials. Part. Fibre Toxicol. 11: 16. https://doi.org/10.1186/1743-8977-11-16

Lee, J.T., Son, J.Y. and Cho, Y.S. (2007). The adverse effects of fine particle air pollution on respiratory function in the elderly. Sci. Total Environ. 385: 28-36. https://doi. org/10.1016/j.scitotenv.2007.07.005

Li, J., Chen, H., Li, X., Wang, M., Zhang, X., Cao, J., Shen, F., Wu, Y., Xu, S., Fan, H., Da, G., Huang, R.j., Wang, J., Chan, C.K., Jesus, A.L. de Morawska, L. and Yao, M. (2019). Differing toxicity of ambient particulate matter (PM) in global cities. Atmos. Environ. 212: 305-315. https://doi.org/10.1016/j.atmosenv.2019.05.048

Manigrasso, M., Vitali, M., Protano, C. and Avino, P. (2018). Ultrafine particles in domestic environments_Regional doses deposited in the human respiratory system. Environ. Int. 118: 134-145. https://doi.org/10.1016/j.envint.2018.05. 049

Mathis, U., Ristimäki, J., Mohr, M., Keskinen, J., Ntziachristos, L., Samaras, Z. and Mikkanen, P. (2004). Sampling conditions for the measurement of nucleation mode particles in the exhaust of a diesel vehicle. Aerosol Sci. Technol. 38: 1149-1160. https://doi.org/10.1080/0278 68290891497

Miller, F.J., Asgharian, B., Schroeter, J.D. and Price, O. (2016). Improvements and additions to the Multiple Path Particle Dosimetry model. J. Aerosol Sci. 99: 14-26. https://doi.org/10.1016/j.jaerosci.2016.01.018

Oh, H.J., Jeong, N.N., Sohn, J.R. and Kim, J. (2019). Personal exposure to indoor aerosols as actual concern: Perceived indoor and outdoor air quality, and health 
performances. Build. Environ. 165: 106403. https://doi.org/ 10.1016/j.buildenv.2019.106403

Pearce, D. (1996). Economic valuation and health damage from air pollution in the deveoping world. Energy Policy 24: 627-630. https://doi.org/10.1016/0301-4215(96)00051-1

Piras, G., Pini, F. and Astiaso Garcia, D. (2019). Correlations of $\mathrm{PM}_{10}$ concentrations in urban areas with vehicle fleet development, rain precipitation and diesel fuel sales. Atmos. Pollut. Res. 10: 1165-1179. https://doi. org/10.1016/j.apr.2019.01.022

Schmid, O. and Stoeger, T. (2016). Surface area is the biologically most effective dose metric for acute nanoparticle toxicity in the lung. J. Aerosol Sci. 99: 133143. https://doi.org/10.1016/j.jaerosci.2015.12.006

Schmid, O. and Cassee, F.R. (2017). On the pivotal role of dose for particle toxicology and risk assessment: Exposure is a poor surrogate for delivered dose. Part. Fibre Toxicol. 14: 52. https://doi.org/10.1186/s12989017-0233-1

Schraufnagel, D.E., Balmes, J.R., Cowl, C.T., De Matteis, S., Jung, S.H., Mortimer, K., Perez-Padilla, R., Rice, M.B., Riojas-Rodriguez, H., Sood, A., Thurston, G.D., To, T., Vanker, A. and Wuebbles, D.J. (2019). Air pollution and noncommunicable diseases: A review by the Forum of International Respiratory Societies' Environmental Committee, Part 1: The damaging effects of air pollution. Chest 155: 409-416. https://doi.org/10.1016/j.chest.2018. 10.042

Scungio, M., Vitanza, T., Stabile, L., Buonanno, G. and Morawska, L. (2017). Characterization of particle emission from laser printers. Sci. Total Environ. 586: 623-630. https://doi.org/10.1016/j.scitotenv.2017.02.030

Stephens, B., Azimi, P., El Orch, Z. and Ramos, T. (2013). Ultrafine particle emissions from desktop 3D printers. Atmos. Environ. 79: 334-339. https://doi.org/10.1016/j.at mosenv.2013.06.050

Swiss National Air Pollution Monitoring Network (NABEL). Daily size distributions from the Zürich NABEL-Station for
February and August 2017. Swiss National Air Pollution Monitoring Network. https://www.bafu.admin.ch/bafu/en /home/topics/air/state/data/national-air-pollution-monitor ing-network--nabel-.html

Tiwari, M., Sahu, S.K., Bhangare, R.C., Yousaf, A. and Pandit, G.G. (2014). Particle size distributions of ultrafine combustion aerosols generated from household fuels. Atmos. Pollut. Res. 5: 145-150. https://doi.org/10.5094/A PR.2014.018

Vallero, D.A. (2019). Air pollution risk calculations. In Air pollution calculations, 1 st edition. Elsevier, Waltham, MA, pp. 335-375

Wang, Y., Hopke, P.K., Chalupa, D.C. and Utell, M.J. (2011). Long-term study of urban ultrafine particles and other pollutants. Atmos. Environ. 45: 7672-7680. https://doi.org/10.1016/j.atmosenv.2010.08.022

World Health Organization (WHO) (2010) IARC Monographs on the Identification of Carcinogenic Hazards to Humans, Agents Classified by the IARC Monographs, Volumes 1-125 (Soot), https://monographs.iarc.fr/list-ofclassifications/

Yeh, H.C. and Schum, G.M. (1980). Models of human lung airways and their application to inhaled particle deposition. Bull. Math. Biol. 42: 461-480. https://doi.org/ 10.1007/BF02460796

Yeh, H.C., Phalen, R.F. and Raabe, O.G. (1976). Factors influencing the deposition of inhaled particles. Environ. Health Perspect. 15: 147. https://doi.org/10.2307/3428398

Zhou, Y., Peng, Z., Seven, E.S. and Leblanc, R.M. (2018). Crossing the blood-brain barrier with nanoparticles. $J$. Controlled Release 270: 290-303. https://doi.org/10.1016 /j.jconrel.2017.12.015

Received for review, January 23, 2020

Revised, March 24, 2020 Accepted, March 31, 2020 